\title{
SOÑANDO INSECTOS: INTERPRETACIÓN POPULAR SEGÚN LOS POBLADORES DE SAN MIGUEL EL GRANDE, OAXACA, MÉXICO
}

\author{
DREAMING OF INSECTS: FOLK INTERPRETATION ACCORDING TO THE \\ INHABITANTS OF SAN MIGUEL EL GRANDE, OAXACA, MEXICO
}

1Juan Carlos APARICIO APARICIO; Eraldo Medeiros COSTA NETO

'Universidade Estadual de Feira de Santana (UEFS), Pós-Graduação em Botânica. E-mail: charly_jan92@hotmail.com

${ }^{2}$ UEFS, Pós-Graduação em Ecologia e Evolução. E-mail: eraldont@hotmail.com

\section{RESUMEN}

Soñar con insectos tiene una larga historia, así como el entusiasmo para su interpretación. El presente trabajo documentado en la subregión mixteca alta, en el estado de Oaxaca, México, tiene como objetivo presentar la importancia que tienen algunos insectos en los sueños de las personas. Entre 2018 y 2019 se realizó un total de 28 entrevistas abiertas y semiestructuradas a hombres y mujeres de las comunidades de estudio. Insectos de cinco taxones (Pediculidae, Diptera, Erebidae, Vespidae y Apidae) fueron nombrados como indicadores de presagios manifestados a través de los sueños de los habitantes. Los sueños con insectos ocupan un lugar importante en la vida de las personas de San Miguel el Grande, ya que vuelven en símbolos de presagios que han sido trasmitidos por generaciones. Palabras-clave: Etnoentomología, Interpretación de sueños, Región Mixteca, Psicoanálisis.

\begin{abstract}
Dreaming about insects has a long history, as well as the enthusiasm for its interpretation. The present documented work in the high Mixtec sub-region, in the state of Oaxaca, Mexico, aims to present the importance of some insects in people's dreams. Between 2018 and 2019, a total of 28 open and semistructured interviews were conducted with men and women from the study communities. Insects from five taxa (Pediculidae, Diptera, Erebidae, Vespidae and Apidae) were named as indicators of omens manifested through the inhabitants' dreams. Insect dreaming occupy an important place in the lives of the people of San Miguel el Grande, as they are to be symbols of omens that have been transmitted for generations.
\end{abstract}

Keywords: Ethnoentomology, Dream interpretation, Mixtec region, Psychoanalysis.

\section{INTRODUCCIÓN}

[...] Tras las huellas del hombre se
convirtieron en cortejo de su historia,
Zumbidos en la vigilia y en el sueño, resguardo
de las siembras asedio de las cosechas [...].

Elva Macías

Si ingenuamente, montáramos una simpática libélula, absurdamente gigantesca y verde-azul como la brócoli y nos diera un paseo con sensaciones de subida y caída hasta aterrizar en un sitio inefable, como los lienzos de Rousseau, donde nos esperan otras libélulas de desordenada coloración que nos hablan, esto no tendría sentido en nuestra vigilia y parece que sí, en el estado de reposo, mas, qué podría significar esa ensoñación (sueño). Según Freud (2017), la interpretación "popular" de los sueños se remota a Artemidorus Daldianus (oniromante y adivino profesional griego, que vivió en la segunda mitad del siglo II d.C). En su obra Oneirocritica, percibe a los insectos como símbolo de preocupaciones y ansiedad (DALDIANUS, 1975). Por su parte, Sigmund Freud demostró una técnica para la interpretación científica de los sueños y los definió como "la actividad anímica del durmiente durante el estado de reposo" (FREUD, 2017). En su obra La interpretación de los sueños (ver la interpretación del sueño del escarabajo de mayo), menciona que todo sueño es interpretable como realización de deseos insatisfechos en la vigilia. Actualmente, los sueños con insectos han sido de gran 
interés multidisciplinario, seguramente por las emociones negativas que estos organismos incitan (KELLERT, 1993).

Los insectos constituyen el linaje más famoso y exitoso de los artrópodos. Con la mayoría de especies de toda la fauna (SCHOWALTER, 2006), dominan nuestro mundo y testificaron en silencio la ascensión de los vertebrados, la declinación de los dinosaurios no-aviarios y la rápida evolución e industrialización de los seres humanos (GRIMALDI y ENGEL, 2005). Brindan un invalorable beneficio al mantenimiento de la vida y a los seres humanos. Realizan interacciones ecológicas como reciclaje de nutrientes, dispersión de hongos y semillas, polinización (GULLAN et al., 2008), así como son modelos biológicos para el monitoreo de las condiciones ecosistémicas dado el papel en la evaluación y mejora de los impactos de la modificación del habitad antropogénico y cambio climático (STEWART et al., 2007). Están presentes en la dieta y medicina de millones de personas alrededor del mundo (RAMOS-ELORDUY, 1982, 1998, 2009; COSTA-NETO, 2004, 2015). Además, en todo el mundo existen referencias de insectos en el pensamiento mágico y religioso de muchas culturas (NAVARIJO, 2006), que supone una riqueza en conocimientos tradicionales.

Lo que se ha denominado como conocimientos tradicionales se refiere al conjunto de saberes y practicas respecto al mundo natural y sobrenatural, trasmitido oralmente de generación a generación por pueblos "indígenas" y no-indígenas (DIEGUES et al., 2000). Es por medio de éstos que las diferentes comunidades humanas se apropian de la naturaleza, lo que les permite moldear su cultura y la supervivencia en el tiempo (ELLEN, 1998). Por ejemplo, el uso de un recurso no solo cubre una necesidad, sino también da identidad al grupo e implica prácticas de manejo para que ese recurso permanezca. Por subsecuente, los conocimientos tradicionales son desarrollados en sistemas complejos de acuerdo a la forma en que cada sociedad se relaciona con el lugar donde habita, difícil de ser entendidos desde un punto de vista exótico (MARQUES, 2002). Así, para entender los conocimientos tradicionales de una determinada comunidad, se requiere de un análisis más amplio respecto al objeto de estudio que se trate; por ejemplo, para un estudio etnoentomológico, comprender el código lingüístico, las actividades productivas y sistema de creencias es crucial para un buen análisis.

Dado que la etnoentomología comprende el estudio de los conocimientos (saberes y creencias) que las personas tienen sobre insectos (MARQUES, 2002), este trabajo discute la forma en que los mixtecos de San Miguel el Grande, Oaxaca, México, han dado significado a los sueños con insectos, en el que los artrópodos protagónicos son dotados de simbolismo para dar sentido al sueño.

\section{MATERIAL E MÉTODOS \\ Área de estudio}

El municipio de San Miguel el Grande pertenece a la subregión mixteca alta del Estado de Oaxaca y se localiza entre las coordenadas UTM 14Q 646792 Oeste y 1885242 Norte; Datum WGS84 (Figura 1). Colinda con San Antonio Xinicahua, San Pedro Molinos, Santa Catarina Ticúa, Chalcatongo de Hidalgo, Santa Catarina Yosonotú, San Esteban Atatlahuca y Tlaxiaco (distrito) (INEGI, 2005). Cuenta aproximadamente con 4.127 habitantes, de los cuales 2.223 son mujeres y 1.904 son hombres (INEGI, 2010). Su clima es frío-templado con lluvias en verano, con una temperatura anual de $10-16^{\circ} \mathrm{C}$.

De acuerdo a la figura anterior, la población está constituida de nueve comunidades y la delegación municipal. Los habitantes hablan español y mixteco. Se practica la agricultura de temporada y ganadería de traspatio. La agricultura de subsistencia se basa en el cultivo del sistema milpa (maíz, frijol, calabaza, chilacayota y habas).

\section{Procedimiento metodológico}

Este trabajo forma parte de un estudio etnoentomológico que se realizó en el municipio de San Miguel el Grande en 2017. Se realizaron entrevistas abiertas y semiestructuradas considerando las tres dimensiones de la Etnoecología Incluyente de Marques (2002): cognitiva, afectiva y comportamental. La investigación tomó como base los principios del código de ética de la Sociedad Latinoamericana de Etnobiología (CANO-CONTRERAS et al., 2015).

Dado la importancia de información respecto a los insectos en los sueños -principalmente de himenópteros- en mayo de 2018 se retornó a la comunidad con la finalidad de profundizar en el tema y realizar controles a través de pruebas de verificación de consistencia y de validez de las respuestas (MARQUES, 1991), recurriendo a entrevistas en situaciones diacrónicas, las cuales suceden cuando 
una pregunta es repetida al mismo individuo en tiempos distintos, en este caso las mismas preguntas hechas en 2017 fueron repetidas en 2018. Se volvió a entrevistar a 17 personas de 28 que habían informado sobre el tema en cuestión. El total de la muestra se constituyó de 21 mujeres y 7 hombres con una edad entre 70 y 91 años de edad.

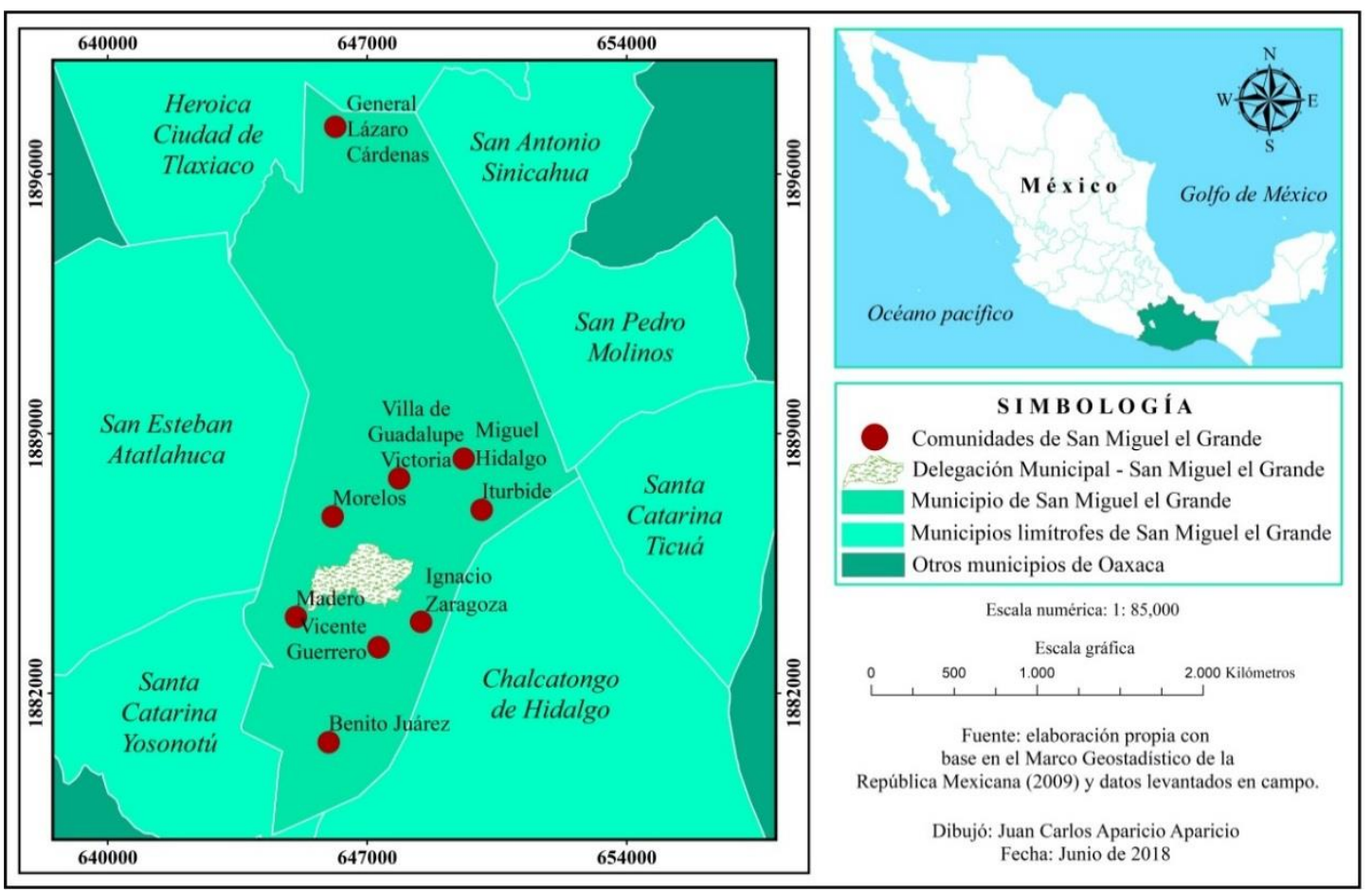

Figura 1: Ubicación geográfica del área de estudio.

\section{RESULTADOS Y DISCUSIÓN}

Para los habitantes de San Miguel el Grande, los sueños constituyen un cúmulo de señales que tienen diferentes propósitos e interpretaciones según el modo y horario en que ocurren; son una forma en que la naturaleza se comunica con las personas, al igual que éstas lo hacen con aquella cuando muestran respeto: al pedir permiso para sembrar o agradecer por la cosecha, por ejemplo. Es a través de los sueños que las fuerzas naturales advierten a la gente de posibles oportunidades, triunfos o amenazas.

De modo general, existen dos tipos de sueños según la gente entrevistada: a) los que revelan los resultados de una actividad; se esperan en la noche inmediata o bien en la madrugada siguiente del día en que se realiza una determinada acción (para conocer los resultados de un ritual por ejemplo); y b) los que suponen presagios para el día en curso, estos son más importantes puesto que su interpretación es incierta; estos son objeto de discusión en el presente.

Insectos situados en cinco familias fueron mencionados como indicadores de presagios manifestados como imágenes oníricas en los sueños. Interpretarlos generalmente es una tarea de las personas de edad más avanzada en el hogar por motivos de experiencia, aunque en ciertos casos no es posible ya que requiere de una especial aptitud de pocas personas en la comunidad; sin embargo, a través del simbolismo que han adquirido estos organismos en los sueños, ya suponen un significado cultural.

Cuando se sueña con piojos blancos (probablemente Pediculus humanus L.) -una especie que estuvo presente en años anteriores y que hoy en día se desconoce su existencia en las comunidadessignifica que se recibirá dinero. Uno de nuestros informantes (profesor jubilado de escuela secundaria) reveló que aunque él no creía en los sueños (de hecho, previamente mencionó que este en particular correspondía a un mito), un día, previo a una cita en las oficinas donde había trabajado, tuvo un sueño en el que blancos piojos saturaban su cabeza, su encuentro fue para notificarle de una suma de dinero, ahorro que efectuó durante su labor y que estaba liberado para retirarlo. Importante destacar hasta qué punto la presencia del molesto anopluro todavía provee el mundo de referencia simbólico y metafísico para los pobladores, quienes aproximadamente a 50 años después de su erradicación aún se remiten a él para dar sentido a una parte de su mundo. 
Este insecto se percibía como exótico en la comunidad, como su clasificación folk lo respalda Chuku rucio: Chuku (genérico en idioma mixteco) y rucio (especifico en español). Probablemente semejante al escaso dinero de esa época que también coincidía en la coloración. Cabe agregar que a diferencia de otras especies de insectos de color blanco, esta vive a expensas del ser humano, por lo que se le recuerda con cierta aversión. No es sorprendente, entonces, que en este contexto los piojos sean los principales protagonistas. El sueño de sobreabundancia de piojos en el cuerpo significa la persistencia de enfermedades, y el sueño con mordidas de pulgas (Pulex irritans L.) significa que se recibirá dinero por una persona humilde (KLEIN, 2012).

A la gente que sueña con gusanos (estadios larvarios de Diptera) que aparecen en materia en descomposición, se les recomienda atenderse en su salud, ya que prevén enfermedades graves que se les avecinan; algunos de estos sueños representan gusanos adheridos en alguna parte del cuerpo, en los objetos personales o alimentos y se sueñan constantemente durante un determinado periodo de tiempo. Aristóteles creía e influenció en médicos la posibilidad de hallar en los sueños la indicación del comienzo de una enfermedad, aun sin experimentar ningún indicio durante la vigilia (SUAREZ, 1980; FREUD, 2017). Según la interpretación científica, el hallarse invadido por insectos parásitos es con frecuencia símbolo del embarazo (FREUD, 2017).

Dos casos involucraron a las mariposas negras (Erebidae) como indicadoras de la presencia de brujería en el cuerpo humano; en uno de ellos, nuestro informante soñaba frecuentemente que pequeñas mariposas negras revoloteaban en la sien derecha de su cabeza, parte donde según él tenía el efecto de la brujería que después curó. En el segundo caso, la informante soñaba que grandes mariposas posaban por un momento en el techo de su vivienda e instantáneamente se elevaban y volvían a posar como si estuvieran vigilando la casa. Ante estos sueños constantes, la paciente preguntó a su curandero por qué esos sueños prevalecían, el curandero afirmó que las personas dedicadas a la magia negra suelen utilizar mariposas negras y otros animales alados para enviar males a sus víctimas, de tal modo que esos sueños representaban avisos.

Con relación a la brujería, en la edad media, las brujas utilizaban a Sphinx atropos en la elaboración de sus pociones (LEVY \& MACHADO, 1999 apud COSTA-NETO, 2002). En la vigilia, las mariposas de color negro han sido un simbolismo asociado a augurios negativos. Los antiguos mexicanos creían que cuando Erebus odora llegaba a la casa de un enfermo, el enfermo moría; de hecho el nombre en idioma náhuatl del lepidóptero se traduce como "Mariposa de la muerte" (HOFFMANN, 1932), en la actualidad esa creencia aún prevalece en varias regiones de México, aunque siempre varea la interpretación y la especie se suele confundir. En Bahia, Brasil, a las mariposas negras también se les reconoce como señal de mal augurio, de tal forma que se interpretan como "cosa mala" y muerte (COSTA-NETO, 2007). En los sueños, las mariposas se han reportado como atrayentes de noticias (GRINNELL, 1899). En el caso de la interpretación de los sueños, las mariposas han sido conceptualizadas como símbolo de renacimiento (CIRLOT, 1992).

Quizá los sueños con insectos que más inquietud provocan sean los que involucran avispas. Según el conocimiento tradicional, el soñar con el ataque y aguijoneadas por un enjambre de avispas prevé la agresión por personas y/o el fallecimiento del soñador. Acerca de estos sueños, una persona relató que un hombre de su comunidad había soñado que algunas avispas lo atacaban y le picaban. Por la tarde cuando bebía unos tragos con otras personas, entre una discusión fue acuchillado por sus acompañantes quienes lo dejaron desangrándose e inconsciente, afortunadamente fue auxiliado y no murió. El contexto que describe el relato da la pauta para argumentar que en el sueño las avispas representaban a las personas agresoras y claramente los aguijones a los cuchillos o más bien, las aguijoneadas a las acuchilladas.

Otra informante describió que su hermano le contó su sueño a su madre una mañana antes de salir a recoger un asno que se desató y causo perjuicios en traspatios del poblado vecino. El sueño contextualizaba un lugar desértico donde feroces avispas le pinchaban repetidamente; cansado e imposibilitado para escapar de los himenópteros, despertó aturdido. Naturalmente, la madre le indicó que el padre lo supliría por precaución; sin embargo, desafiando la situación partió a su labor; el hombre murió cuando regresaba a su casa. Éste caso resulta sumamente interesante porque el hombre fue envenenado cuando bebió una copa de aguardiente en las tierras limítrofes. De acuerdo a la discusión con la informante de este sueño, hay varios elementos sugestivos a exponer: el veneno de las avispas parecía indicar la causa de la muerte del hombre (envenenamiento); "la imposibilidad del hombre" de hecho mostraba que no lograría librarse de la muerte. Más aun, el lugar desértico se interpreta como la ausencia de ayuda. 
En las dos citas anteriores se pudo constatar a través de la denominación en el idioma nativo (Mixteco) que se trataba de avispas, pero en otros casos con información imprecisa no se logró determinar si se refieren a avispas, ya que los informantes manifestaron una confusión en diferenciar avispas de abejas, por lo que estas últimas también pueden estar ligadas a estos sueños. Por su parte, a las abejas se les ubicó esencialmente en sueños que suponen escenas de pleitos en el hogar (con la pareja), con los miembros de la familia o con personas ajenas (disputa o daño de bienes). Cabe agregar que ambos insectos han causado la muerte de humanos y ganado de traspatio, tal vez por ello soñar con estos himenópteros constituya un simbolismo de peligro próximo.

Análogamente, las picaduras de avispas en los sueños se han mencionado como problemas y peligro por delante: días llenos de pena (interpretación árabe), traición y ataques peligrosos (interpretación europea), y los sueños con abejas augura confusiones y problemas (KLEIN, 2012). En la interpretación griega, los enjambres suelen revestir un significado maligno debido a que son interpretados como fuerzas en disolución pululantes; "lo múltiple es siempre de signo negativo" (CIRLOT, 1992), como antítesis, la miel suele ser un símbolo positivo por socorrer al ser humano.

A los organismos que se conexionan con las personas a través de los sueños, no se les denigra o considera de mal agüero por este hecho, porque se argumenta que son "avisos naturales" que en algunos casos no son entendidos por la gente y en otros, son ignorados. Los Guaraní Nandéva de la aldea de Pirajuí, en Mato Grosso do Sul, Brasil, afirman que el Tupã Guasu (dueño de la naturaleza) les revela la clasificación y los insectos que pueden ser utilizados como alimento a través de los sueños (VERA y BRAND, 2012).

Es importante explicar que a casi todos los tipos de insectos se les atribuye al menos una acción negativa en su forma tangible, por ello es probable que esta característica esté directamente relacionada en cómo esa información está organizada en el subconsciente del individuo, que hasta cierto punto puede ser una proyección del subconsciente: los piojos se percibían como insoportables; los gusanos, como indicadores de putrefacción; las mariposas, se les tiene cierta aversión (a las de color negro); las abejas y avispas se consideran peligrosas por la función de su mecanismo de defensa. Como menciona Hillman (1988), los sueños demuestran las intenciones de la mente natural, la fe inquebrantable del deseo y la necesidad de sobrevivir. En este sentido, pueden comunicar la conciencia comunitaria de un enjambre o una colmena como un Gemeinschaftsgefuehl (sentido de la comunidad) (HILLMAN, 1983; 1988).

Como caso excepcional, se cita los sueños de un pequeño apicultor que soñaba con abejas cada vez que tenía contacto con estos organismos durante el día, quien interpretaba como reclamos o felicidad de la colmena. Los mayas del municipio de Dzidzantún en Yucatán le atribuyen a la mantis religiosa (Mantodea) ser generadora de sueños que no permiten descansar, después de haber sido molestada durante el día (RIVAS-GARCÍA et al., 2017).

\section{CONCLUSIONES}

Los sueños con insectos ocupan un lugar trascendente en la vida de las personas dado el papel mediador que desempeñan, representando un simbolismo muy marcado como presagios y no se les denigra por esta cualidad aun cuando el significado cultural pueda ser negativo. La información sobre los sueños pueden ser no experimentada, resultado en esencia de la trasmisión de los conocimientos tradicionales, como sucede con los sueños con himenópteros que reciben especial importancia en la comunidad de San Miguel el Grande, donde personas con esta información pueden no haber tenido ninguna experiencia e incluso no haber escuchado ningún relato probatorio, aun así saben que el sueño con abejas supone una experiencia "mala" o "peligrosa" y el que tienen qué recordar con reflexión ante las actividades que desempeñen.

Al considerar nuestros resultados, los insectos son, entonces, indicadores de presagios en su forma intangible, a través de los sueños, resultado de una construcción simbólica en el subconsciente del ser humano. De este modo, el nivel de importancia que tienen los insectos en los sueños de una determinada cultura también puede manifestar que tan importante han sido las interacciones de estos artrópodos con generaciones pasadas del grupo cultural, como el caso de Pediculus humanus, pues nuestros sueños recuperan lo que el mundo olvida (HILLMAN, 1988). 


\section{REFERENCIAS}

CANO-CONTRERAS, E. J.; MEDINACELI, A.; SANABRIA-DIAGO, O. L.; ARGUETA, A. Código de ética para la investigación, la investigación-acción y la colaboración etnocientífica en América Latina. Versión dos. Etnobiologia, v. 13, Suplemento n. 1, p. 1-28, 2015.

COSTA-NETO, E. M. Insetos como recursos alimentares nativos no semi-árido do estado da Bahia, Nordeste do Brasil. Zonas Áridas, v. 8, p. 33-40, 2004.

COSTA-NETO, E. M. Anthropo-entomophagy in Latin America: an overview of the importance of edible insects to local communities. Journal of Insects as Food and Feed, 2015, DOI 10.3920/JIFF2014.0015.

COSTA-NETO, E. M. A Utilização Ritual de Insetos em Diferentes Contextos Socioculturais. Sitientibus Série Ciências Biológicas, v. 2 (1/2), p. 97-103, 2002.

COSTA-NETO, E. M. Los ángeles tienen escamas: las mariposas en los diferentes contextos socioculturales. In: NAVARRETE-HEREDIA, J. L.; QUIROZ-ROCHA G. A.; FIERROS-LÓPEZ H. E. (Coord.) Entomología Cultural: Una Visión Iberoamericana, Universidad de Guadalajara, Guadalajara, 2007.

CIRLOT, J. E. Diccionario de símbolos. $9^{\text {na }}$ ed., Labor, Barcelona España, 1992.

DIEGUES, A. C. et al. Saber tradicional, ciência e biodiversidade. In: Biodiversidade e comunidades tradicionais no Brasil. São Paulo: NUPAUB-USP, PROBIO-MMA \& CNPq, 2000. p. 30-35.

DALDIANUS, A. The Interpretation of Dreams; Oneirocritica. Translation of White R.J. Noyes Press; Park Ridge, NJ, USA: 1975.

FREUD, S. The Interpretation of Dreams. Traslation of Brill A. A. Digireads,com Publishing, 2019.

GRIMALDI, D.; ENGEL, M. S. Evolution of the insects. New York: Cambridge University Press, 2005.

GULLAN, P. J.; CRANSTON, R. S. The insects: an outline of entomology. $3^{\mathrm{a}}$ ed., Blackwell publishing, UK. 2005.

GRINNELL, G. B. The butterfly and spider among the Blackfeet. Am. Anthropol.: 1:194-196. 1899.

HILLMAN, J. "Going Bugs". Spring: A Journal of Archetype and Culture. 40-72. 1988.

HILLMAN, J. Hillman, James. 1983. Archetypal Psychology: A Brief Account. Dallas, Texas: Spring Publications. 1983.

HOFFMANN, C. C. Las mariposas entre los antiguos mexicanos. Anales del Museo Nacional de Arqueología, Historia y Etnografía, v. 7, n. 2, p. 422-125, 1932.

INSTITUTO NACIONAL DE ESTADÍSTICA Y GEOGRAFÍA (INEGI). Geoestadístico municipal. Oaxaca, 2005.

INSTITUTO NACIONAL DE ESTADÍSTICA Y GEOGRAFÍA (INEGI). Censo de población y vivienda. México, 2010.

KELLERT, S. R. Values and perceptions of invertebrates. Conservation. Biology.: 7:845-855. 1993.

KLEIN, B. A. The curious connection between insects and dreams. Insects. 3, 1-17, 2012. doi: 10.3390/insects3010001.

MARQUES, J. G. O olhar (des)multiplicado. O papel do interdisciplinar e do qualitativo na pesquisa etnobiológica e etnoecológica. In: AMOROZO, M. C. M.; MING, L. C.; SILVA, S. M. P. (Orgs.). Métodos de coleta e análise de dados em etnobiologia, etnoecologia e disciplinas correlatas. Rio Claro: UNESP/CNPq, 2002. p. 31-46.

MARQUES, J. G. W. Aspectos ecológicos na etnoictiologia dos pescadores do Complexo Estuarino-lagunar Mundaú-Manguaba. 1991. 292 f. Tese (Doutorado em Ecologia) - Universidade Estadual de Campinas, Campinas, 1991.

NAVARIJO, M. L. Percepciones e importancia de los insectos en el ámbito urbano de la ciudad de México, México. Sitientibus, Série Ciências Biológicas 6(4): 334-342. (2006).

RAMOS-ELORDUY, J. Los insectos como fuente de proteína en el futuro. México, D.F.: Limusa, 1982.

RAMOS-ELORDUY, J. Creepy crawly cuisine: the gourmet guide to edible insects. Vermont: Park Street Press, 1998.

RAMOS-ELORDUY, J. Anthropo-entomophagy: cultures, evolution and sustainability. Entomological Research, v. 39, p. 271-288, 2009.

RIVAS-GARCÍA, G.; AGUILAR, W.; GARCÍA, G.; TUN, J.; MANRRIQUE, P.; PINKUS-RENDÓN, M. A. Estudio etnoentomológico de los insectos aprovechados por los ejidatarios de Dzidzantún, Yucatán, México. Etnobiologia. V. 15, p. 67-78, 2017.

STEWART, J. A.; NEW, T. R.; LEWIS O. T. Insect conservation biology. Londres: Royal Entomological Society, 2007.

SUÁREZ, E. El sueño y la fenomenología onírica en Aristóteles. CFC 5 (1973) 279-311. VAN LIESHOUT, J., Greeks on Dreams, Utrecht, 1980.

VERA, C.; BRAND, A. Aramanday guasu (Rhynchophorus palmarum) como alimento tradicional entre os Guarani Ñandéva na aldeia Pirajuí. Tellus, v. 12, 2012. 